\title{
CORRELATION OF HYPONATRAEMIA IN CHILDREN WITH LOWER RESPIRATORY TRACT INFECTION - AN INSTITUTIONAL OBSERVATIONAL STUDY
}

\author{
Kanchan S. Channawar ${ }^{1}$, Namita Deshmukh², VSV Prasad ${ }^{3}$ \\ ${ }^{1}$ Consultant Paediatrician, Lotus Hospital for Women and Children, Lakadikapul, Hyderabad. \\ ${ }^{2}$ Consultant Paediatrician, Lotus Hospital for Women and Children, Lakadikapul, Hyderabad. \\ ${ }^{3}$ Chief Paediatrist, Intensivist and Neonatologist, Lotus Hospital for Women and Children, Lakadikapul, Hyderabad.
}

ABSTRACT

\section{BACKGROUND}

Hyponatraemia is the most common electrolyte disorder in children hospitalized for various reasons. India being developing country, pneumonia remains a significant cause of morbidity and mortality. Electrolyte disturbances especially hyponatraemia (serum sodium $<135 \mathrm{mEq} / \mathrm{L}$ ) have been described in a wide variety of acute infections including pneumonia.

The aim of this study was to identify the incidence of hyponatraemia and its association with morbidity, mortality and duration of hospital stay in children with LRTI.

\section{MATERIALS AND METHODS}

This was a retrospective, descriptive and observational study conducted during the period of 24 months with children of 2 months to 5 years hospitalised in PICU and general paediatric ward due to lower respiratory tract infection. Information on variables including the child's age and gender, clinical features of pneumonia, duration of hospitalisation, non-specific markers of inflammation and biochemical examinations (Urea, creatinine, sodium) were also recorded. The study group was subdivided into two groups based on hyponatraemia: groups with or without hyponatraemia. Frequency of hyponatraemia was calculated for the total sample and in relation to age, sex and expressed as percentage.

\section{RESULTS}

The study population consisted of 209 children. The mean age of patients was $19.17 \pm 15.54$ months, their age ranged from 1 to 60 months. There was hyponatraemia (serum sodium < $135 \mathrm{mmol} / \mathrm{L}$ ) in 54/209 (24.88\%) patients, ten had moderate hyponatraemia and three had severe hyponatraemia. Hypernatraemia was observed in $26(12.44 \%)$ of our patients. The duration of their hospitalisation was $4.16 \pm 2.34$ days.

\section{CONCLUSION}

Our findings confirm that mild hyponatraemia is common among children hospitalised with pneumonia, though more common in severe pneumonia. Thus, serum electrolytes should be measured in children hospitalised for pneumonia. The appropriate fluid therapy must be carefully arranged in children with hyponatraemia.

\section{KEYWORDS}

Pneumonia, Hyponatraemia.

HOW TO CITE THIS ARTICLE: Channawar KS, Deshmukh N, Prasad VSV. Correlation of hyponatraemia in children with lower respiratory tract infection - an institutional observational study. J. Evolution Med. Dent. Sci. 2016;5(88):6533-6535, D0I: $10.14260 /$ jemds/2016/1478

\section{BACKGROUND}

The recent advances made in the medical field with newer antibiotics and immunisation has reduced the incidence of lower respiratory tract infection in the developed world. However, pneumonia is still the leading cause of death in children younger than 5 years in developing countries accounting for approximately $20 \%$ of childhood deaths.(1) Children admitted with pneumonia are critically ill and often times have complications, which include electrolyte abnormalities, the commonest being hyponatraemia. Studies done in the Western countries have shown up to $45.4 \%$ of children hospitalised with pneumonia had hyponatraemia.(2-4)

Financial or Other, Competing Interest: None.

Submission 12-08-2016, Peer Review 22-10-2016,

Acceptance 28-10-2016, Published 02-11-2016.

Corresponding Author:

Dr. Kanchan S. Channawar,

Lotus Hospital for Women and Children,

Lakadikapul, Hyderabad.

E-mail:drkanchanc@yahoo.co.in

DOI: $10.14260 /$ jemds $/ 2016 / 1478$
The precise mechanism is unknown, but primary illness, impaired water excretion, inappropriate release of vasopressin, use of hypotonic fluids, redistribution of sodium and water and several drugs may contribute to hyponatraemia.(5)

The aim of this study is to find the incidence of hyponatraemia and its association with morbidity, mortality and duration of hospital stay in children with LRTI.

\section{MATERIALS AND METHODS}

The records of children aged 2 months to 5 years hospitalised in PICU and paediatric ward due to lower respiratory tract infection were analysed retrospectively. The study population were randomly chosen from those who were admitted to hospital from January 2013 to March 2015. The children with Cardiac disease, Kidney disorders, Central nervous system infections, gastroenteritis and children who are on drugs which can cause electrolyte imbalance such as diuretics, anticonvulsants were excluded from the study. Data on demographic variables including the age and gender and duration of hospital stay were also recorded. 
Laboratory data included complete blood cell count, CReactive Protein (CRP), Erythrocyte Sedimentation Rate (ESR), serum concentrations of Sodium (Na), creatinine, urea, blood gas analysis and random blood glucose level. Disease severity was assessed by respiratory distress, respiratory support needed and duration of hospitalisation. The study group was divided into two groups based on serum sodium levels: groups with hyponatraemia and without hyponatraemia. Hyponatraemia was defined as a sodium concentration of < $135 \mathrm{mmol} / \mathrm{L}$ in serum. A serum sodium concentration of 131$134 \mathrm{mmol} / \mathrm{L}$ represents mild hyponatraemia, 126-130 mmol/L moderate hyponatraemia and $\leq 125 \mathrm{mmol} / \mathrm{L}$ severe hyponatraemia. Hypernatraemia was defined as a serum sodium concentration $>145 \mathrm{mmol} / \mathrm{L}$.

Frequency of hyponatraemia was calculated for all the patients and in relation to age, sex and expressed as percentage. Statistical significance of comparisons was determined by chi-square test or Fisher's exact test for proportions, whichever was appropriate. $\mathrm{P}$ value $<0.05$ was considered as statistically significant.

\section{RESULTS}

In this study, total 209 children were included. The mean age of patients was $19.17 \pm 15.54$ months, their age ranged from 1 to 60 months and 133 of them (54\%) were boys. On admission, the patient's serum sodium concentrations ranged from 124 $\mathrm{mmol} / \mathrm{L}$ to $155 \mathrm{mmol} / \mathrm{L}$. There was hyponatraemia (serum sodium < $135 \mathrm{mmol} / \mathrm{L}$ ) in 54/209 (24.88\%) patients, of whom 10 had moderate hyponatraemia and 3 had severe hyponatraemia. The mean serum sodium concentration was $138.37 \pm 5.63 \mathrm{mmol} / \mathrm{L}$. Hypernatraemia was observed in 26 $(12.44 \%)$ of our patients.

Cough and fever were the predominant presenting features. At admission temperature was variable, fluctuating between $98.6^{\circ} \mathrm{F}$ and $105.5^{\circ} \mathrm{F}$. Fever was present for $0-30$ days (3.578 days) before entrance to the hospital and lasted for 0.0 - 4.0 days ( 1 day) after admission day. Cough was present 0.0 - 30.0 days before admission in children with pneumonia. The mean duration of their hospitalisation was $4.16 \pm 2.34$ days.

No significant differences were found in serum urea in the patients with hyponatraemia, normal serum sodium or hypernatraemia. None had oedema or dehydration, suggesting fluid balance was normal. No significant difference was observed in haemoglobin, CRP, thrombocyte count, ESR and duration of hospitalisation between the two groups.

In other words, the serum sodium levels negatively correlated with acute phase reactants. Also, according to the results of linear regression analysis, the mean leucocyte count was the only significant independent predictor of serum sodium levels.

Correlations were also performed between the two groups concerning body temperature at admission $\left({ }^{\circ} \mathrm{F}\right)$, duration of fever before and after admission, respiratory distress and duration of hospitalisation. In group with hyponatraemia the duration of fever, respiratory distress was significantly higher than the one without hyponatraemia. We could not find out any correlation with clinical markers such as height of temperature at admission and heart rate.

There was a correlation between the need of respiratory support in terms of oxygen therapy, invasive or non-invasive ventilation. The need for oxygen therapy and ventilation were more $(18.52 \%, 3.70 \%)$ in hyponatraemia than the no hyponatraemia $(7.10,2.58 \%)$, though there was no significant difference in the duration of hospitalisation in both the groups.

\section{DISCUSSION}

Hyponatraemia is a common finding in children hospitalised with various diseases and also with pneumonia. Usually, it comprises part of the syndrome of inappropriate SIADH.(6-8) SIADH occurs in about one-third of children hospitalised for pneumonia and is associated with a more severe disease and a poorer outcome.(6) ADH secretion results in retention of water with slight weight gain, usually with no oedema formation and normal blood pressure. Dhawan A et al have shown that hyponatraemia was the most frequent electrolyte abnormality in children hospitalised due to pneumonia and was associated with a more severe disease and a poorer outcome, (4) which is similar to other studies. $(5,9)$ The present study showed that hyponatraemia was a frequent finding in children with pneumonia $(24.88 \%)$ and in majority of cases, hyponatraemia was mild. Ten had moderate hyponatraemia and three had severe hyponatraemia. Mild hyponatraemia is usually asymptomatic, but severe hyponatraemia is usually associated with central nervous system symptoms and can be lifethreatening. We did not observe any complications related to hyponatraemia in any patient even with severe hyponatraemia in our study. Gerigk et al found that antidiuretic hormone release induced hyponatraemia may originate in a non-osmotic, cardiovascular mechanism in acutely ill children including children with pneumonia.(8) The analysis of two studies in children with pneumonia has shown a significant association between the presence of hyponatraemia and elevated levels of non-specific inflammatory markers.(2,10) Such correlation was not observed in our study. Although, in the previous two studies, it was reported that hyponatraemia seemed to be associated with the longer hospitalisation period and a prolonged duration of fever, there was no such relationship in our study. $(2,10)$

Studies have also demonstrated that respiratory compromise is a comorbid factor in patients with hyponatraemia markedly increasing the risk of death from pneumonia. The underlying mechanism is probably hypoxia, a major risk factor for the development of hyponatraemic encephalopathy. ${ }^{(9)}$ In our study, we did not observe mortality in patients even with severe hyponatraemia. Small sample size is limitation of our study. Larger studies are needed in order to assess whether hyponatraemia could impact the outcome of hospitalised children with severe pneumonia.

\section{CONCLUSION}

From our observation we found that mild hyponatraemia is common among children admitted with pneumonia, though more common in severe pneumonia. Thus, serum electrolytes should be measured in children hospitalised for pneumonia; the appropriate fluid therapy must be carefully arranged in children with hyponatraemia.

\section{REFERENCES}

1. Zar HJ, Madhi SA. Childhood pneumonia-progress and challenges. SAMJ 2006;96(9 Pt 2):890-900.

2. Subba Rao SD, Thomas B. Electrolyte abnormalities in children admitted to pediatric intensive care unit. Indian Pediatr 2000;37(12):1348-53. 
3. Prasad SV, Singhi S, Chugh KS. Hyponatremia in sick children seeking pediatric emergency care. Indian Pediatr 1994;31(3):287-94.

4. Singhi S, Dhawan A. Frequency and significance of electrolyte abnormalities in pneumonia. Indian Pediatr 1992;29(6):735-40.

5. Don M, Valerio G, Korppi M, et al. Hyponatremia in pediatric community-acquired pneumonia. Pediatr Nephrol 2008;23(12):2247-53.

6. Haviv M, Haver E, Lichtstein D, et al. Atrial natriuretic peptide in children with pneumonia. Pediatr Pulmonol 2005;40(4):306-9.
7. Haycock GB. The syndrome of inappropriate secretion of antidiuretic hormone. Pediatr Nephrol 1995;9(3):37581.

8. Gerigk M, Gnehm HE, Rascher W. Arginine vasopressin and renin in acutely ill children: implication for fluid therapy. Acta Paediatr 1996;85(4):550-3.

9. Arieff AI, Ayus JC, Fraser CL. Hyponatraemia and death or permanent brain damage in healthy children. BMJ 1992;304(6836):1218-22.

10. Sakellaropoulou A, Hatzistilianou M, Eboriadou M, et al. Hyponatraemia in cases of children with pneumonia. Arch Med Sci 2010;6(4):578-83. 